\title{
EGFR-TKI resistance and MAP17 are associated with cancer stem cell like properties
}

\author{
YI SHAO $^{1}$, HUI LV ${ }^{1}$, DIAN-SHENG ZHONG ${ }^{1}$ and QING-HUA ZHOU ${ }^{2}$ \\ ${ }^{1}$ Department of Oncology; ${ }^{2}$ Tianjin Lung Cancer Center and Institute, \\ Tianjin Medical University General Hospital, Tianjin 300052, P.R. China
}

Received February 11, 2017; Accepted January 19, 2018

DOI: $10.3892 / \mathrm{ol} .2018 .8129$

\begin{abstract}
Patients with non-small-cell lung cancer (NSCLC) with sensitive epidermal growth factor receptor (EGFR) mutations generally react well to tyrosine kinase inhibitors (TKIs). However acquired resistance eventually occurs. Several mechanisms contribute to the resistance including T790M mutation, c-Met amplification and PIK3CA mutation. In recent years, cancer stem cells (CSCs) have been suggested to be involved in TKI resistance. MAP17 is aberrantly overexpressed in a number of malignancies. However, the expression pattern and function of MAP17 in CSCs are still unclear. The aim the present study was to illustrate the effect of CSC-like cells on the resistance to TKIs in EGFR mutant NSCLC cells and explore the possible role of MAP17 in CSCs. The EGFR mutant cell line PC9 was cultured under serum-deprived undifferentiated conditions. The CSC properties including expression of stem cell markers CD133, CD44, Oct-4 and ABCG2, ability of self-renewal, invasion, proliferation and tumorigenesis were examined. The expression of MAP17 was compared in sphere and parent cells. Sphere cells displayed stem cells phenotypes and were resistant to erlotinib. Sphere cells expressed higher levels of MAP17, and MAP17 was associated with self-renewal and TKI resistance. The function of MAP17 demonstrated to be partially dependent on Na-dependent glucose transporter 1 . Collectively these findings suggest that MAP17 serves a role in TKI resistance through regulation of CSCs in lung cancer.
\end{abstract}

Correspondence to: Dr Yi Shao, Department of Oncology, Tianjin Medical University General Hospital, 154 Anshan Road, Heping, Tianjin 300052, P.R. China

E-mail: shaoshao_0709@aliyun.com

Abbreviations: NSCLC, non-small-cell lung cancer; EGFR, epidermal growth factor receptor; TKI, tyrosine kinase inhibitor; EMT, epithelial-to-mesenchymal transition; CSC, cancer stem cell; ROS, reactive oxygen species; SGLT1, Na-dependent glucose transporter 1; SP, side population; FACS, fluorescence activated cell sorting; PI3K, phosphatidylinositol 3-kinase; ABC, ATP-binding cassette

Key words: cancer stem cell, epidermal growth factor receptor, MAP17, resistance, tyrosine kinase inhibitor

\section{Introduction}

Lung cancer is one of the most common malignancies worldwide and non-small-cell lung cancer (NSCLC) accounts for $\sim 80 \%$ of all lung cancers (1). The majority of patients with NSCLC are at an advanced stage of disease when initially diagnosed. The standard treatment for advanced disease includes chemotherapy and, for patients with sensitive gene mutations, targeted therapy (2). Multiple studies have demonstrated that patients with sensitive epidermal growth factor receptor (EGFR) mutations respond to tyrosine kinase inhibitors (TKIs) well, with an overall response rate of $55-80 \%(3,4)$. However, patients with EGFR mutant NSCLC develop disease progression 8-16 months after TKI administration, which has been defined as 'acquired resistance' (5). Mechanisms underlying the phenomenon of acquired resistance include a secondary mutation T790M, c-Met amplification, PIK3CA mutation and epithelial-to-mesenchymal transition (EMT) (6). However, these account for only 50-70\% of the mechanisms responsible (7), and the remaining mechanisms still require elucidation. A previous study demonstrated that an erlotinib resistant NSCLC cell line expressed markers of cancer stem cell (CSC) CD44high/CD24low, and could form spheres more efficiently (8). Consequently, during a long exposure to TKIs, the appearance and enrichment of CSCs may be one of the causes of acquired resistance (9).

CSCs are a small reservoir of tumor cells with ability of self-renewal, unlimited proliferation and differential potential, and are the principal causes of tumor growth, relapse, metastasis and drug-resistance (10). Dependent on the clonogenic ability of CSCs, sphere cells rich in CSCs could be acquired under a suspension culture deprived of serum. Based on this hypothesis, the aim of the present study was to culture lung sphere cells, examine the features of CSCs and identify an association, if present, between stem cell-like cells and TKI resistance.

MAP17, also termed PDZKIIP1, is a membrane-associated non-glycosylated protein of $17 \mathrm{kDa}$ located on the cell membrane and the Golgi apparatus. MAP17 protein includes a PDZ combining domain and two transmembrane regions. MAP17 is abnormally overexpressed in several malignant tumors including carcinoma of the breast, thyroid, cervix and lung (11). Tumors overexpressing MAP17 exhibited increased malignant phenotypes, including ability of proliferation, 
invasion, migration and tumorigenesis (12-14). However, the function of MAP17 in lung CSCs remains unclear. The present study identified that MAP17 expression was upregulated in lung CSC-like cells. MAP17 expression was positively associated with self-renewal and TKI resistance. Collectively, MAP17 may promote TKI resistance through the regulation of CSCs.

\section{Materials and methods}

Cell culture. The PC9 cell line were provided by Tianjin Lung Cancer Institute (Tianjin, China) and cultured in Dulbecco's modified Eagle's medium (DMEM) containing $10 \%$ fetal bovine serum (FBS) (HyClone; GE Healthcare Bio-Sciences, Logan, UT, USA), $100 \mathrm{U} / \mathrm{ml}$ penicillin, and $100 \mathrm{mg} / \mathrm{ml}$ streptomycin at $37^{\circ} \mathrm{C}$ in $5 \% \mathrm{CO}_{2}$ atmosphere. Cells were stained with $0.1 \%$ crystal violet at room temperature for 15 min and observed with an Inverted Microscope TS100 (Nikon Corporation, Tokyo, Japan) at x400 magnification.

Sphere formation assay. PC9 Cells were digested with $0.25 \%$ trypsin for $3 \mathrm{~min}$ and single cells were cultured in DMEM/F12 supplemented with 50x B-27 (Gibco; Thermo Fisher Scientific, Inc., Waltham, MA, USA), $20 \mathrm{mg} / \mathrm{ml}$ epidermal growth factor (EGF) and $10 \mathrm{ng} / \mathrm{ml}$ basic fibroblast growth factor (bFGF) (PeproTech, Inc., Rocky Hill, NJ, USA) without serum on ultralow attachment plates (Corning Incorporated, Corning, NY, USA) at a density of 5,000 cells $/ \mathrm{ml}$. After 3-7 days, spheres began to form. Cells that exceeded 4 passages were used for subsequent experimentation.

Limited dilution. Sphere and parent cells were diluted via a 10x gradient with the corresponding medium (sphere cells, DMEM/F12 supplemented with 50x B-27, $20 \mathrm{mg} / \mathrm{ml}$ EGF and $10 \mathrm{ng} / \mathrm{ml} \mathrm{bFGF}$; parent cells, DMEM with $10 \% \mathrm{FBS}$ ) to 5 cells $/ \mathrm{ml}$, then $100 \mu \mathrm{l}$ of cell suspension was added into 96-well plate and incubated at $37^{\circ} \mathrm{C}$ for $24 \mathrm{~h}$. The wells containing a single cell were marked. Following a 7-day incubation, cells were observed with an inverted microscope at x400 magnification, and a clone with >10 cells was considered to be a sphere. Sphere formation rate was calculated as=wells containing a sphere/wells containing a single cell $\mathrm{x} 100(\%)$.

Fluorescence-activated cell sorting (FACS). Sphere and parent cells were digested with $0.25 \%$ trypsin into single cell suspension and incubated with $10 \mu \mathrm{l}$ phycoerythrinconjugated CD133 (1:10; cat. no. 130-109-166) or CD44 (1:20; cat. no. 130-110-121) antibody (Miltenyi Biotech $\mathrm{GmbH}$, Bergisch Gladbach, Germany) for $30 \mathrm{~min}$ at $4^{\circ} \mathrm{C}$. Mouse IgG2-phycoerythrin (1:10; cat. no. 130-092-215; Miltenyi Biotech $\mathrm{GmbH}$ ) was used as an isotype control. The labeled cells were analyzed by BD FASCCanto II flow cytometer (BD Biosciences, Franklin Lakes, NJ, USA) according to the manufacturer's protocol and data was analyzed with FlowJo v10 software (Tree Star, Inc., Ashland, OR, USA). Gating was set on the basis of negative-control staining profiles.

MTT assay. Sphere and parent cells were seeded in 96-well plates at a density of $3 \times 10^{3}$ cells/well in triplicate. Cells were incubated for either $24,72,120$ or $168 \mathrm{~h}$ at $37^{\circ} \mathrm{C}$. Cells were then incubated with MTT $(5 \mathrm{mg} / \mathrm{ml})$ for $4 \mathrm{~h}$ at $37^{\circ} \mathrm{C}$. The formazan crystals were solubilized with $150 \mu \mathrm{l}$ DMSO for $10 \mathrm{~min}$. The level of MTT/formazan was determined by measuring absorbance at a wavelength of $570 \mathrm{~nm}$ using a microplate reader (SPECTRA; Tecan Group, Ltd., Mannedorf, Switzerland).

Drug treatmenst. Sphere and parent cells were treated with different concentrations of cisplatin $(1,5,10,20,40$, and $100 \mu \mathrm{g} / \mathrm{l})$ and erlotinib $(0.1,1,10,40$, and $100 \mu \mathrm{mol} / \mathrm{l})$ in $200 \mu \mathrm{l}$ medium for $48 \mathrm{~h}$ at $37^{\circ} \mathrm{C}$. Cells were then treated with MTT as previously described. The $50 \%$ inhibitive concentration $\left(\mathrm{IC}_{50}\right)$ of cisplatin for sphere cells and parent cells were $17.81 \pm 1.13$ and $8.73 \pm 0.56 \mu \mathrm{g} / \mathrm{l}$ respectively. A concentration of $8 \mu \mathrm{g} / \mathrm{l}$ cisplatin was selected for subsequent experimentation. The $\mathrm{IC}_{50}$ of erlotinib for sphere cells and parent cells were $53.61 \pm 1.10$ and $3.71 \pm 0.42 \mu \mathrm{mol} / 1$. A concentration of of $3 \mu \mathrm{mol} / 1$ erlotinib was selected for the subsequent experimentation. As for SGLT1 inhibitor phloridzin, cells were treated with $50 \mu \mathrm{mol} / 1 \mathrm{phloridzin}$ for $48 \mathrm{~h}$ for the following experiments.

Transwell invasion assay. Sphere and parent cells $\left(2 \times 10^{4}\right.$ cells/well) were cultured in triplicate in the upper chamber of Transwell plates that were loaded with $100 \mu \mathrm{l}$ of diluted matrigel (BD Biosciences, Franklin Lakes, NJ, USA). DMEM with $10 \%$ FBS was added in the lower chamber. Following a $48 \mathrm{~h}$ incubation at $37^{\circ} \mathrm{C}$, the migrated cells at the bottom of the membrane were fixed with $95 \%$ ethanol and visualized using $10 \%$ crystal violet at room temperature for $15 \mathrm{~min}$. Cells were counted using an inverted microscope TS100 (Nikon Corporation, Tokyo, Japan) at a x400 magnification. A total of 5 random fields were selected in each chamber to quantify the invading cells.

In vivo xenograft assay. Tumorigenicity was assayed by the subcutaneous injection of $5 \times 10^{5}$ sphere or parent cells into the back legs of 4 week-old female non-obese diabetic-severe combined immunodeficiency (NOD/SCID) mice purchased from Laboratory Animal Center of Beijing Tumor Research Institute (Beijing, China). A total of 24 mice were randomly divided into two groups. There were 12 mice in each group and mice were kept in $23 \pm 2^{\circ} \mathrm{C}$ temperature-controlled environment with a $12 \mathrm{~h}$ dark/12 $\mathrm{h}$ light cycle and free access to food and water. The overall health, body weights of the animals and the tumor volumes were examined twice weekly, and every other day following the establishment of tumors. Tumor formation rate was defined as the ratio of the number of mice with tumor formation compared with the total number of mice. The tumor size was calculated using the formula: $\mathrm{V}$ (volume) $=1 / 2 \mathrm{x}$ length $\mathrm{x}$ width $^{2}$. The permitted maximum tumor size was $1 \mathrm{~cm}^{3}$. All mice were anesthetized and sacrificed with an overdose of anesthetic on day 56 after injection or when the tumor reached the maximum projective size. All animal experiments were performed according to Animal Research: reporting of in vivo experiments (ARRIVE) guidelines, the Animal Welfare Act 2006, and the experimental protocol were reviewed and approved by the Experimental Animal Ethical Committee of Tianjin Medical University (Tianjin, China). 
Reverse transcription-quantitative polymerase chain reaction (RT-qPCR). The total RNA of sphere and parent cells was extracted using TRIzol Reagent (Thermo Fisher Scientific,Inc.). The first strand cDNA was synthesized using a PrimeScript RT reagent kit (Takara Bio, Inc., Otsu, Japan) at $37^{\circ} \mathrm{C}$ for $15 \mathrm{~min}$, then $85^{\circ} \mathrm{C}$ for $5 \mathrm{sec}$, according to the manufacturer's protocol. The following primers were synthesized by Sangon Biotech Co., Ltd. (Shanghai, China) to amplify specific cDNA regions: Oct-4, forward: 5'-GGTGGAAGCTGACAACA-3' and reverse: 5'-ATCTGCTGCAGTGTGGGTTT-3'; ABCG2, forward: 5'-CACCTTATTGGCCTCAGGAA-3' and reverse: 5'-CCTGCTTGGAAGGCTCTATG-3'; CD133, forward: 5'-CAGATGCTCCTAAGGCTTG-3' and reverse: 5'-GCA AAGCATTTCCTCAGG-3'; MAP17, forward: 5'-CAGCCA TGTCGGCCCTCA-3' and reverse: 5'-TTATTTCACAGA AATTAGGGCC-3'; $\beta$-actin, forward: 5'-AGGCCAACCGCG AGAAGATGAC-3' and reverse: 5'-GAAGTCCAGGGCGAC GTAGCA-3'. qPCR was performed in the ABI PRISM 7500 Sequence Detection system (Applied Biosystems; Thermo Fisher Scientific, Inc.) using SYBR ${ }^{\circledR}$ Fast qPCR Mix (Takara Bio, Inc.). Relative expression level was determined using the $2^{-\Delta \Delta C \mathrm{q}}$ method (15). The thermocycling conditions were as follows: $95^{\circ} \mathrm{C}$ for $15 \mathrm{sec}, 60^{\circ} \mathrm{C}$ for $60 \mathrm{sec}, 72^{\circ} \mathrm{C}$ for $30 \mathrm{sec}$, for a total of 40 cycles. Agarose gel electrophoresis was performed following the reaction, and the products were observed using an ultraviolet imaging system.

Stable transfection with MAP17. PC9 cells were seeded on 6 -well plates at a density of $1 \times 10^{5}$ cells/well. When cell distribution reached $60-70 \%$, cells were transfected with the pcDNA3.1-MAP17 and pcDNA3.1 plasmids using Lipofectamine 2000 (Invitrogen; Thermo Fisher Scientific, Inc). Following $48 \mathrm{~h}$, the transfected cells were cultured with a medium containing G418 (800 $\mu \mathrm{g} / \mathrm{ml}$; Sigma-Aldrich, Merck KGaA, Darmstadt, Germany) to eliminate nontransfected cells. G418-resistant colonies were isolated and expanded. Following this, positively-transfected cells were identified by determining whether MAP17 was expressed stably by qPCR and western blot analysis. The subsequent experiments were performed $72 \mathrm{~h}$ after transfection.

Western blot analysis. The cells were lysed in RIPA buffer (Roche, Basel. Switzerland) and centrifuged at 14,000 x g for $15 \mathrm{~min}$ at $4^{\circ} \mathrm{C}$. The protein was quantified with the BCA Protein Assay kit (Beyotime Institute of Biotechnology, Shanghai, China). The individual cell lysates ( $20 \mu \mathrm{g} /$ lane) were separated by $12 \%$ sodium dodecyl sulfate polyacrylamide gel electrophoresis and transferred onto polyvinylidene fluoride membranes. The membranes were blocked with $5 \%$ fat-free dried milk in TBST at room temperature for $1 \mathrm{~h}$ and then incubated with relevant primary antibodies (Oct-4, dilution 1:500, cat. no. sc-101534; cABCG2, 1:500, cat. no. sc-69989; $\beta$-actin, dilution 1:1,000, cat. no. sc-130065; Santa Cruz Biotechnology, Inc., Dalas, TX, USA; MAP17, 1:400, cat. no. ab31405; SGLT1, dilution 1:400, cat. no. ab14686; Abcam, Cambridge, UK) at $4^{\circ} \mathrm{C}$ overnight. After washing with PBS with $0.1 \%$ Tween-20, the membranes were incubated with the horseradish peroxidase-conjugated goat anti-mouse secondary antibodies (1:2,000; cat. no. GTX213111-01; GeneTex, Irvine, $\mathrm{CA}, \mathrm{USA}$ ) at $37^{\circ} \mathrm{C}$ for $1 \mathrm{~h}$. The bands were detected by enhanced chemiluminescence detection reagents (Applygen Technologies, Inc., Beijing, China).

Cell cycle analysis. The cell cycle was examined by a Cell Cycle Detection kit (BD Biosciences), according to the manufacturer's protocol. A total of $1 \times 10^{6}$ sphere or parent cells were centrifuged at $1,000 \mathrm{x} \mathrm{g}$ for $5 \mathrm{~min}$ and washed twice with PBS. The cells were then suspended in $500 \mu \mathrm{l}$ ice-cold $70 \%$ ethanol and incubated at $4{ }^{\circ} \mathrm{C}$ overnight. The fixed cells were centrifuged at $1,000 \mathrm{x}$ g for $5 \mathrm{~min}$ and then washed with PBS. Following incubation with $200 \mu \mathrm{l}$ RNase A $(1 \mathrm{mg} / \mathrm{ml})$ at $37^{\circ} \mathrm{C}$ for $30 \mathrm{~min}$ in the dark, the cells were resuspended in $800 \mu \mathrm{l}$ propidium iodide $(50 \mu \mathrm{g} / \mathrm{ml})$ and placed in the dark at $4^{\circ} \mathrm{C}$ for $30 \mathrm{~min}$. The stained cells were analyzed using BD FASCCanto II flow cytometer (BD Biosciences).

RNA knockdown. Cells were transfected with the small interfering RNAs (siRNAs) in 6-well plates. For each transfection, $250 \mu 1$ of 100 pmol siRNA was mixed with $250 \mu 1$ of HiPerFect Transfection reagent (Qiagen GmbH, Hilden, Germany) and $2 \mathrm{ml}$ of Optimem medium (Invitrogen, Thermo Fisher Scientific, Inc). After $10 \mathrm{~min}$ of incubation at room temperature, the $2.5 \mathrm{ml}$ transfection mix was distributed to each well and incubated at $37^{\circ} \mathrm{C}$ for $72 \mathrm{~h}$. The following specific siRNAs were used: siRNA PDZK1 (cat. no. SI04314723), and AllStars negative control siRNA (cat. no. SI03650318, both purchased from Qiagen $\mathrm{GmbH}$ ).

Statistical analysis. All the experiments were performed in triplicate and the data are presented as mean \pm standard deviation. A two-tailed paired Student's t-test was used for statistical analysis. $\mathrm{P}<0.05$ was considered to indicate a statistically significant difference. Statistical analyses and graphics were produced using the GraphPadPrism software version 5 (GraphPad Software, Inc., La Jolla, CA, USA).

\section{Results}

Tumor spheres exhibit stemness. CSCs can be enriched with suspension cultivation in anchorage independent conditions based on their clonogenic ability (16). Consequently, the present study examined whether spheres could be formed in a serum-deprived suspension culture. Following 3 days of culture, the spheres formed and could generate $>8$ generations stably (Fig. 1A). When seeded in clonogenic density, single cell could still form second-generation spheres, which excluded the possibility of cell adhesion and proved single clonality.

CSCs were previously identified using stem cell surface markers, among which CD133 and CD44 are the most frequently used $(17,18)$. The expression of CD133 and CD44 were compared between sphere and parent cells by FACS. The CD133 positivity of sphere cells was $7.80 \pm 0.53 \%$, while $0.23 \pm 0.06 \%$ of parent cells (Fig. 1B). The rate of sphere cells expressing CD44 was $98.60 \pm 0.26 \%$, and $98.01 \pm 0.06 \%$ in parent cells (Fig. 1C).

Stem-like cells have been demonstrated to have the ability of self-renewal, invasion, proliferation and differentiation (19). To determine whether sphere cells harbor these stem-like properties, the potential of self-renewal was compared by limited dilution. The results demonstrated that sphere cells 

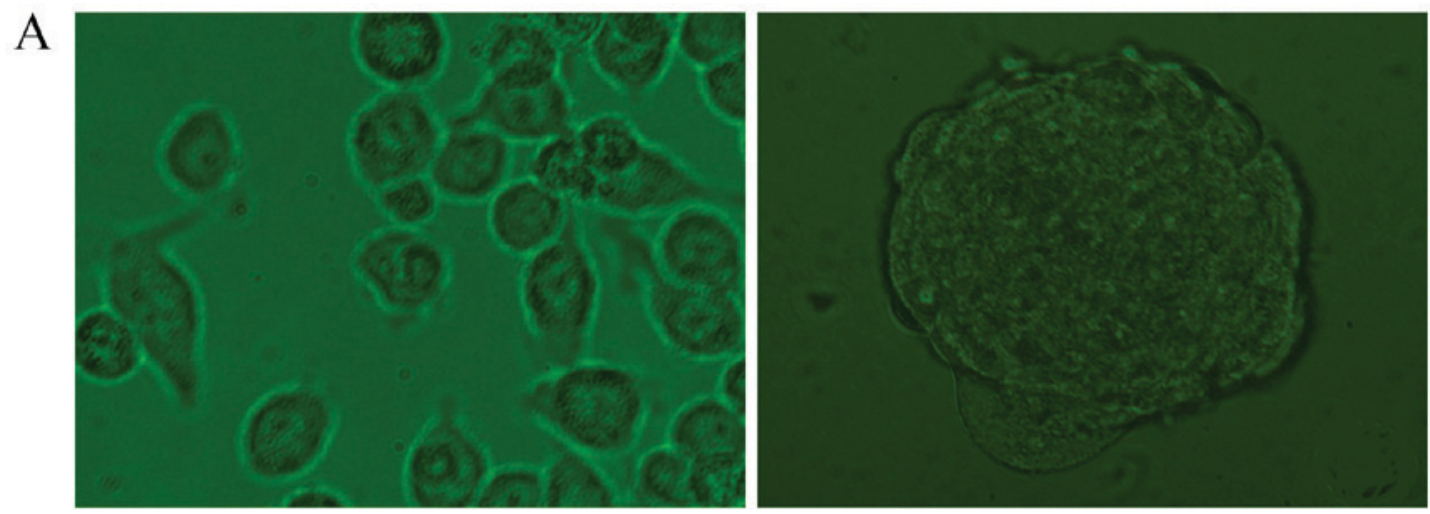

B
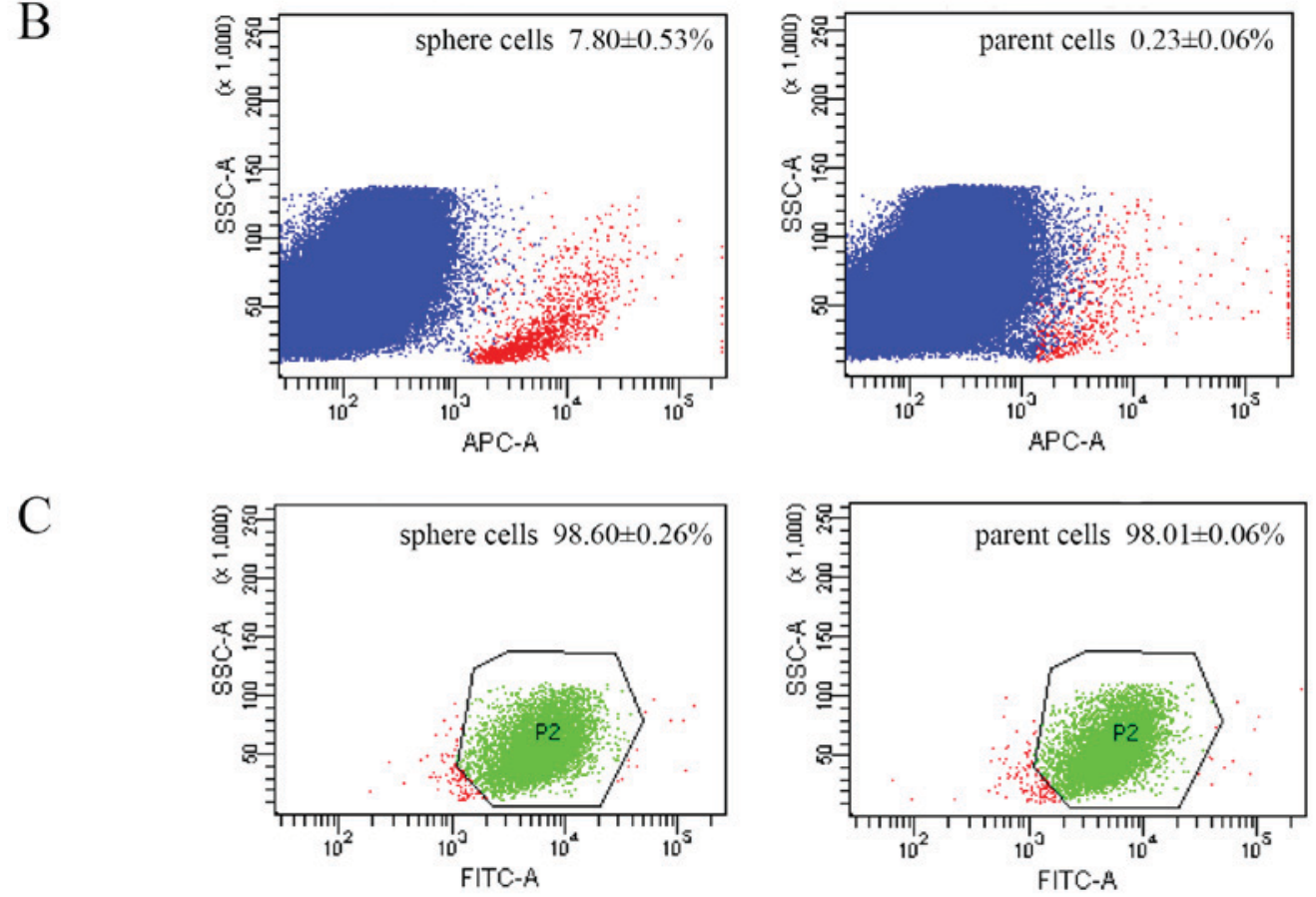

Figure 1. Morphology and stem markers of sphere cells. (A) Morphology of parent tumor cells (left) and sphere cells (right) (magnification x400). (B) CD133 expression of sphere and parent cells by FACS (red: CD133+; blue: CD133-). (C) CD44 expression of sphere and parent cells by FACS (green: CD44+; red: CD44-). FACS, fluorescence activated cell sorting; FITC, fluorescein isothiocyanate.

had improved sphere formation capabilities (Fig. 2A). The proliferation rate was compared by MTT assay, and the growth curve demonstrated a higher proliferation ability in sphere cells (Fig. 2B). Cell invasion ability was also examined. The invasive ability of spheres was significantly higher when compared with parent cells (Fig. 2C). Sphere cells were then planted in normal cultural condition in DMEM medium containing 10\% FBS for $48 \mathrm{~h}$ and the appearance of differentiated cells were similar to parent tumor cells (Fig. 2D). Following a 5-day culture the percentage of CD133-positive cells of sphere cells was $7.80 \pm 0.53 \%$, and that of differentiated cells was $0.32 \pm 0.08 \%$, which demonstrated sphere cells could differentiate into common tumor cells (Fig. 2D and E).

A number CSCs overexpress Oct-4 and ABCG2, which are respectively associated with maintenance of self-renewal and drug resistance $(20,21)$. Therefore, the present study examined the mRNA levels of Oct- 4 and ABCG 2 of spheres by RT-qPCR. The mRNA expressions of Oct- 4 and ABCG2 of sphere cells were statistically higher than that of parent cells (Fig. 3A and B). Then western blotting was used for the measurement of protein expression and a notable difference of Oct- 4 and ABCG2 levels were detected between sphere, parent and differentiated cells. The expression level of Oct- 4 in spheres was markedly higher when compared with those of parent and differentiated cells; however, no evident difference was observed between the parent and differentiated cells. Similarly, the expression of ABCG2 in spheres was higher than that of the parent and differentiated cells, and the difference in expression of ABCG2 in parent cells was not evident compared with differentiated cells (Fig. 3C). Although insignificant, the expressions of Oct- 4 and ABCG2 were higher in differentiated cells than parent cells, potentially $48 \mathrm{~h}$ is not sufficient time for CSC-like cells to fully differentiate.

Tumorigenesis is the definitive indicator of CSCs (17). Therefore the present study examined the ability of tumorigenesis of sphere cells and parent PC9 cells in vivo. The results demonstrated that tumors began to form in the experimental group in the fourth week, while in the control group, tumors did not begin to form until the sixth week. The rate of tumor 
A

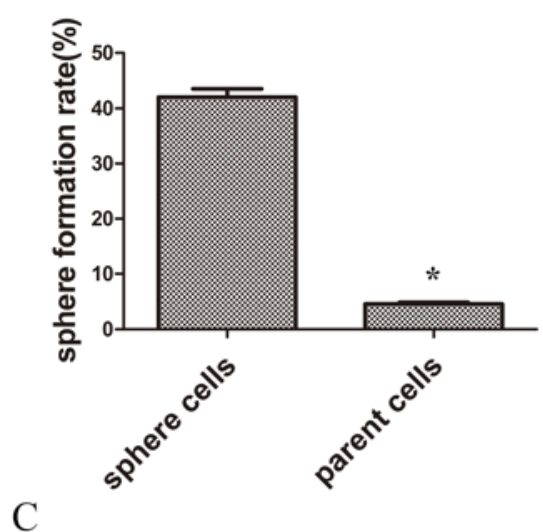

C
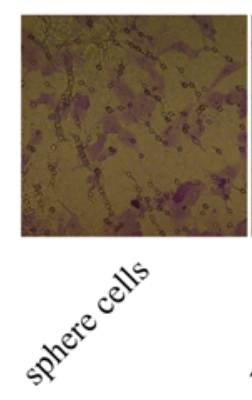

D

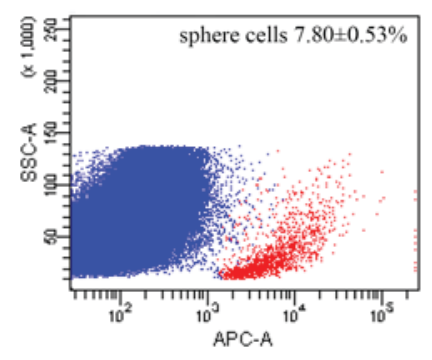

B

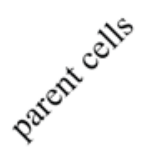

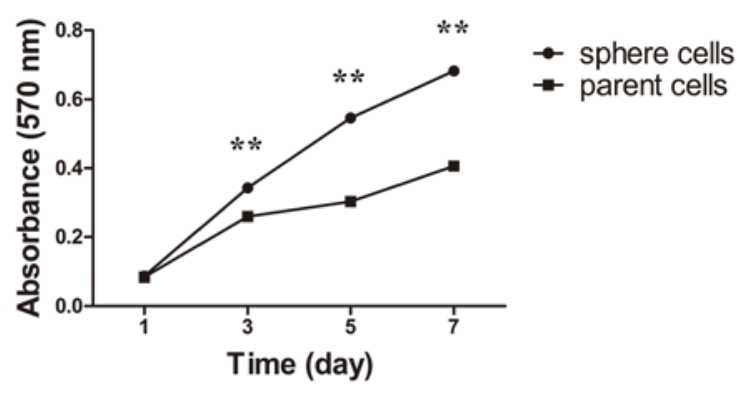
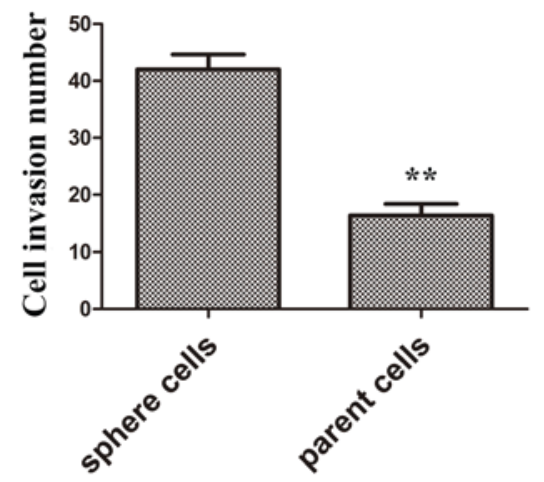

E

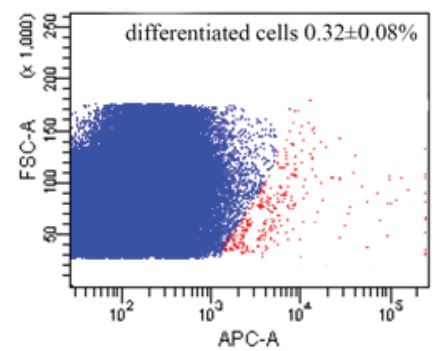

Figure 2. Stem properties of self-renewal, proliferation, invasion and differentiation of sphere and parent tumor cells. (A) Sphere formation rates of sphere and parent cells. (B) MTT assay of growth curve of sphere and parent cells. (C) The ability of invasion was compared between sphere and parent cells by Tranwell assay (cells were stained with $0.1 \%$ crystal violet, magnification x400). (D) CD133 was tested by FACS in sphere and differentiated cells (red: CD133+; blue: CD133-). (E) Morphology of differentiated cells detected by phase-contrast microscopy (x400 magnification). FACS, fluorescence activated cell sorting. ${ }^{*} \mathrm{P}<0.01$ vs. sphere cells, ${ }^{* *} \mathrm{P}<0.05$ vs. sphere cells.

formation in sphere groups was $100 \%$, and $66.7 \%$ in parent cells group. The tumor growth curve showed the sphere cells gave rise to significantly higher tumor volumes than the parent cells (Fig. 3D and E).

Drug resistance and influences of TKI on sphere and parent tumor cells. To elucidate whether stem cells had an increased resistance to drugs, sphere and parent cells were treated with the chemotherapeutic drug cisplatin or the targeted drug erlotinib. The results demonstrated that sphere cells possessed a stronger capacity for drug resistance in cisplatin and erlotinib when compared with parent cells. Spheres and parent cells treated with different concentrations of cisplatin and erlotinib for $48 \mathrm{~h}$ showed statistically different growth inhibition rate curve (Fig. 4A and B).
Then the apoptosis rate was tested. Following treatment with erlotinib $3 \mu \mathrm{mol} / 1$ for $48 \mathrm{~h}$, the apoptosis rates of sphere and parent cells increased. Apoptosis rate of spheres prior to and following treatment with erlotinib were $4.42 \pm 0.28$ and $5.79 \pm 0.43 \%$, while apoptosis rate of normal tumor cells prior to and following treatment with erlotinib were $4.27 \pm 0.23$ and $31.37 \pm 1.50 \%$. Normal tumor cells showed a much higher proportion of apoptosis following treatment with erlotinib (Fig. 4C).

As for cell cycle distribution, following treatment with erlotinib ( $3 \mu \mathrm{mol} / \mathrm{l})$ for $48 \mathrm{~h}$, the proportions of $\mathrm{G} 0 / \mathrm{G} 1, \mathrm{~S}$ and G2/M of sphere cells were not statistically different. However, the proportions of G0/G1 and G2/M were notably increased in parent cells and the propotion of $\mathrm{S}$ of parent cells was decreased (Fig. 4D). 
A

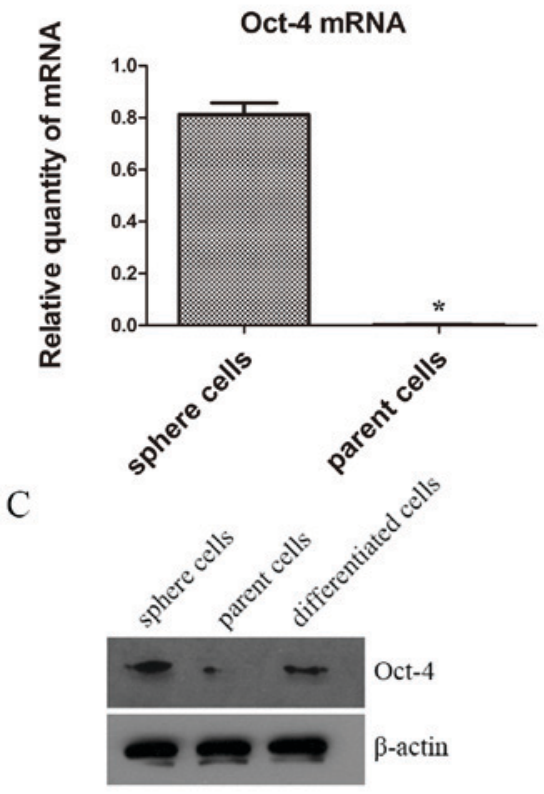

$\mathrm{D}$

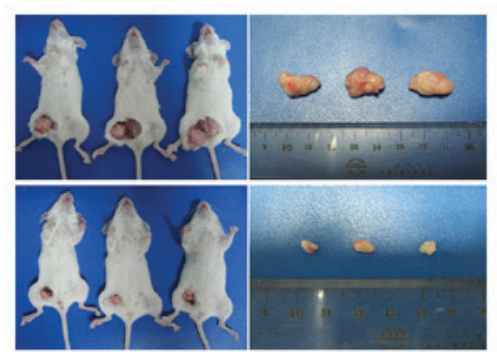

B

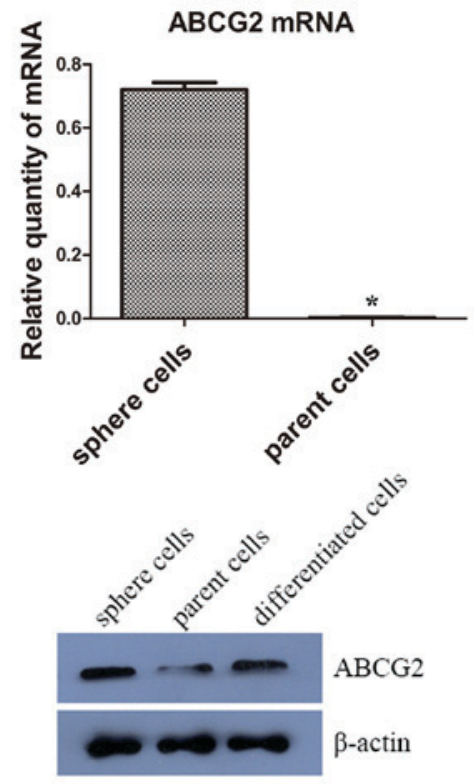

$\mathrm{E}$

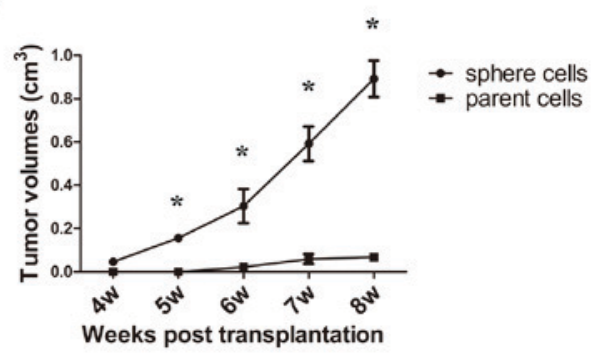

Figure 3. Oct-4 and ABCG2 levels and tumorigenesis of sphere and parent tumor cells. (A) mRNA levels of Oct-4 by RT-qPCR of sphere and parent cells. (B) mRNA levels of ABCG2 by RT-qPCR of sphere and parent cells. (C) Protein levels of Oct-4 and ABCG2 of sphere and parent cells by western blot analysis. (D) Tumorigenesis in vivo of sphere and parent cells. (E) Tumor volumes in sphere and parent cells. ${ }^{*} \mathrm{P}<0.05$ compared between sphere and parent cells. RT-qPCR, reverse transcription-quantitative polymerase chain reaction.

The change of levels of ABCG2 and CD133 following erlotinib treatment were investigated in sphere cells, and the expression of ABCG2 and CD133 were significantly elevated following erlotinib treatment (Fig. 4E and F).

MAP17 expression was upregulated and associated with TKI resistance in CSCs. In order to investigate whether MAP17 participates in the regulation of lung CSCs, the expression pattern of MAP17 on CSC-like and parent cancer cells were examined using RT-qPCR and western blot analysis. The results revealed that the expression level of MAP17 was increased in sphere cells, in mRNA (Fig. 5A) and protein levels (Fig. 5B). To determine whether MAP17 had a role in CSC phenotype of self-renewal, MAP17 was knocked-down in sphere cells using siRNA. MTT assays were performed $48 \mathrm{~h}$ after erlotinib treatment to examine cell viability. The results showed that following MAP17 knockdown, sphere cells became less resistant to erlotinib (Fig. 5C). Additionally, the results demonstrated that knockdown of MAP17 decreased the sphere formation efficiency of CSC-like cells (Fig. 5D).
To further confirm the function of MAP17, MAP17 was overexpressed in parent cells. After a $48 \mathrm{~h}$ treatment with erlotinib, cells overexpressing MAP17 were increasingly resistant to erlotinib compared with their control counterparts (Fig. 5E). Self-renewal was also examined and cells overexpressing MAP17 exhibited a higher sphere formation efficiency than the control group (Fig. 5F).

Na-dependent glucose transporter 1 (SGLT1) overexpression is associated with MAP17 and CSC phenotypes. It was reported that MAP17 harbored the ability of tumorigenesis by increasing endogenous reactive oxygen species (ROS) (22). The increased ROS activates AKT and significantly decreases c-myc-induced apoptosis through SGLT1 activation (23), and the suppression of SGLT1 inhibits MAP17-induced ROS increase and tumor cell proliferation (24). Therefore, examined SGLT1 expression levels of the tumor cells. It was revealed that SGLT1 expression was increased in MAP17 overexpressed tumor cells (Fig. 5G). Furthermore, treatment with the SGLT inhibitor phloridzin could decrease the sphere formation slightly but significantly (Fig. $5 \mathrm{H}$ ). 
A

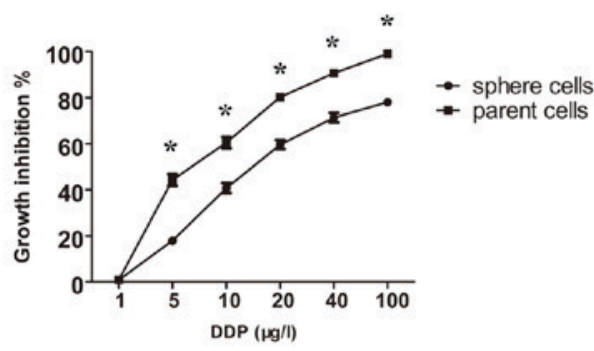

C

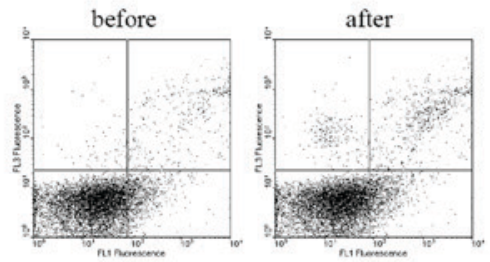

sphere cells

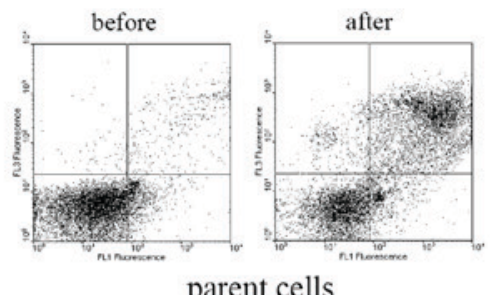

parent cells

D
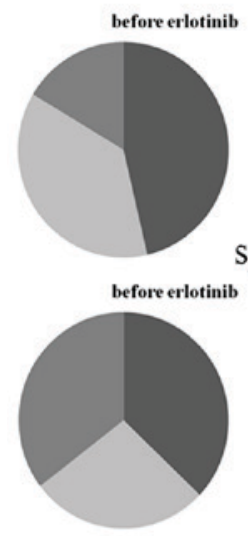

sphere cells
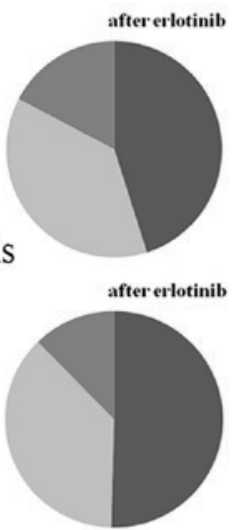

parent cells
B
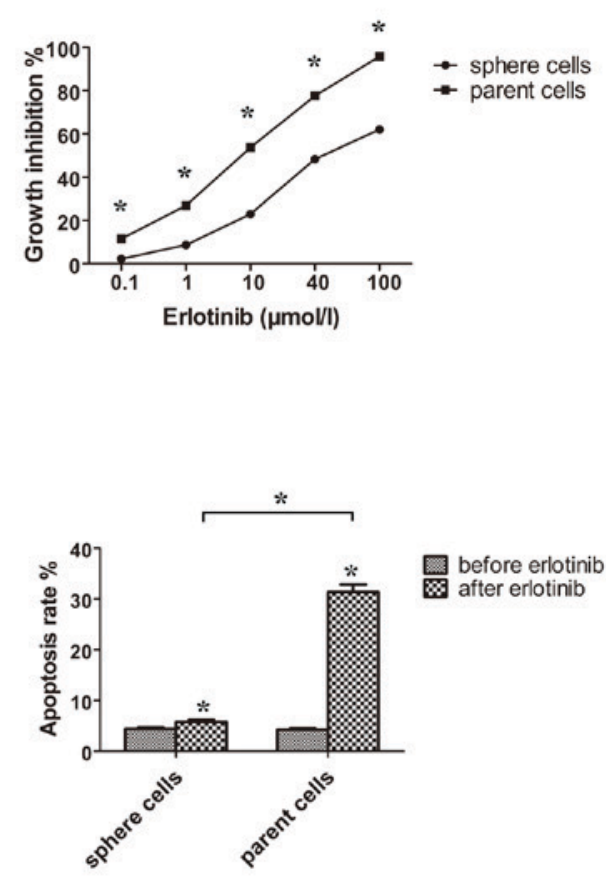

E

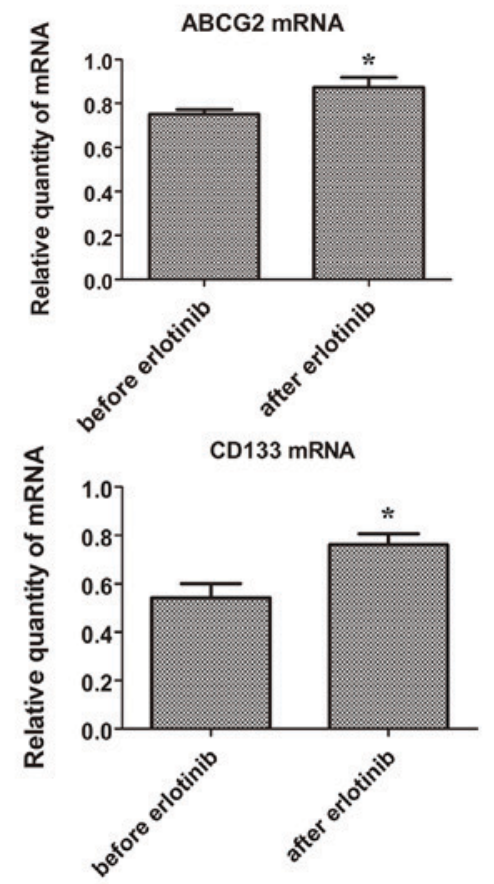

Figure 4. Drug resistance and change of apoptosis, cell cycle and markers under treatment of TKI. (A) MTT assay of sphere and parent cells under treatment of indicated concentration of cisplatin for $48 \mathrm{~h}$. (B) MTT assay of sphere and parent cells under treatment of indicated concentration of erlotinib for $48 \mathrm{~h}$. (C) Apoptosis rate detected by FACS before and after treatment of erlotinib ( $3 \mu \mathrm{mol} / \mathrm{l})$ for $48 \mathrm{~h}$ of sphere and parent cells. (D) Change of cell cycle distribution tested by FACS before and after treatment of erlotinib ( $3 \mu \mathrm{mol} / \mathrm{l})$ for $48 \mathrm{~h}$ of sphere and parent cells. (E) mRNA levels of ABCG2 by RT-qPCR of sphere cells treated after $48 \mathrm{~h}$ of erlotinib $(3 \mu \mathrm{mol} / \mathrm{l})$. (F) mRNA levels of CD133 detected by RT-qPCR of sphere cells treated after $48 \mathrm{~h}$ of erlotinib $(3 \mu \mathrm{mol} / \mathrm{l}) .{ }^{*} \mathrm{P}<0.05$ compared between sphere and parent cells. FACS, fluorescence activated cell sorting; RT-qPCR, reverse transcription-quantitative polymerase chain reaction; DDP, cisplatin.

\section{Discussion}

At present, there is growing concern about the resistance to EGFR-TKIs. In the present study, CSC-like cells were enriched with a serum-deprived suspension culture, and found the sphere cells bore stem cell-like properties and were resistant to erlotinib. Sphere cells expressed higher levels of MAP17, and MAP17 was associated with self-renewal and TKI resistance. 
A

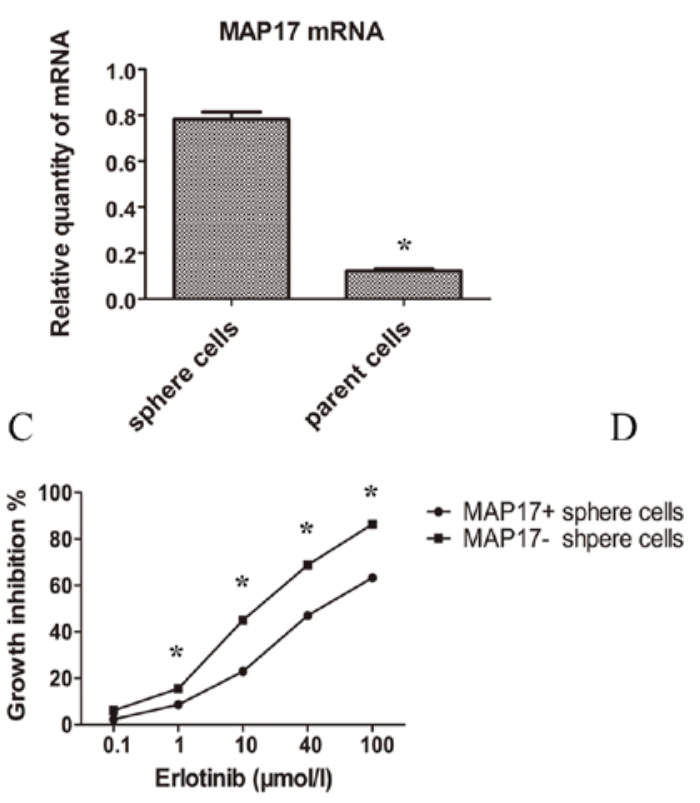

E

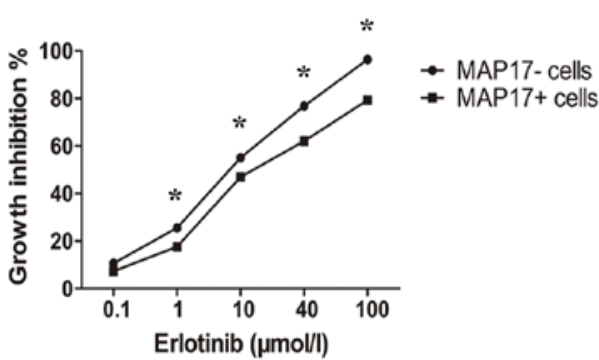

G

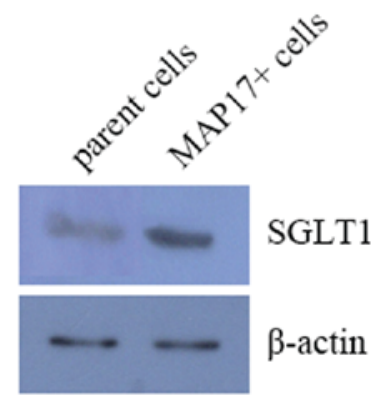

B

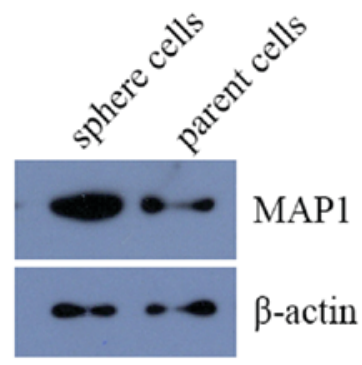

F

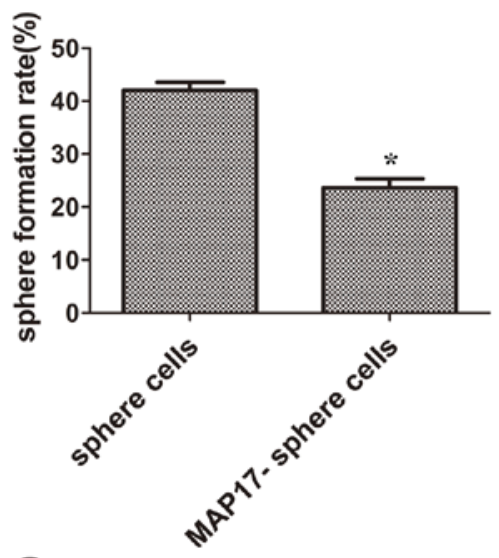

$\mathrm{H}$
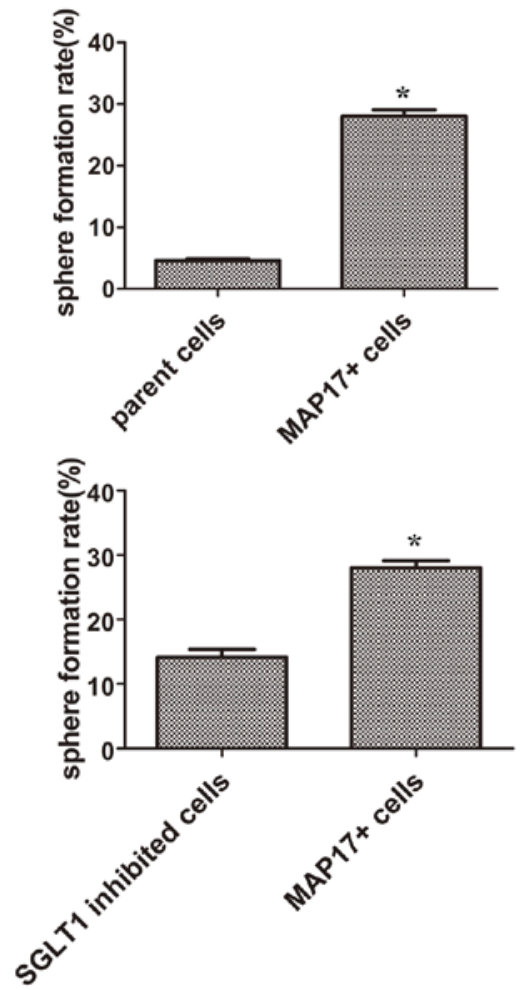

Figure 5. Expression and influence of MAP17 on TKI resistance and stemness. (A) mRNA levels of MAP17 of sphere and parent cells detected by RT-qPCR. (B) Protein levels of MAP17 of sphere and parent cells detected by western blot analysis. (C) MTT assay of sphere cells and sphere cells with knockdown of MAP17. Erlotinib was added $72 \mathrm{~h}$ post siRNA transfection. Cancer cells were treated with indicated concentration of erlotinib for $48 \mathrm{~h}$. (D) Sphere formation rate of sphere cells and sphere cells with knockdown of MAP17. (E) MTT assay of parent PC9 cells and PC9 cells overexpressing MAP17. Erlotinib was added $48 \mathrm{~h}$ post transfection. Cancer cells were treated with indicated concentration of erlotinib for $48 \mathrm{~h}$. (F) Sphere formation rate of parent PC9 cells and PC9 cells overexpressing MAP17. (G) Protein levels of SGLT1 detected by western blot analysis of PC9 cells and PC9 cells overexpressing MAP17. (H) Sphere formation rate of parent PC9 cells and PC9 cells overexpressing MAP17 after treatment of SGLT inhibitor ploridzine. "P<0.05 compared between sphere and parent cells. SGLT, Na-dependent glucose transporter 1.

CSCs are defined as tumor cells capable of self-renewal and able to generate heterogenetic tumor cells (10). Cancer is regarded as a stem-cell disease, and CSCs serve an important role in tumorigenesis, proliferation, metastases and drug 
resistance (25). CSCs are usually identified based on their biological functions and specific cell surface markers, and stem cell surface markers have been used to purify CSCs. Among which, CD133, CD44, Oct-4, sox-2 are the most commonly used $(17,18,20,21)$. Additionally side population (SP) cells manifest significant abilities of invasiveness and tumorigenesis, and express drug-resistance related proteins such as ABCG2, therefore SP cells are considered to exhibit stemness. SP cells are capable of 'pumping out' dyes including Hoechst 33324, therefore the unstained cells are identifiable by fluorescence activated cell sorting (FACS) (26). Furthermore, CSCs hold the ability of colony forming, so enriching spheroid cells in an undifferentiated suspension condition is an effective way of purifying and identifying CSC-like cells. Under these conditions, cells form spheres, express stem cell markers like Oct-4 and Bmil, and the ability of self-renewal could also be tested (16). In the present study, sphere cells manifested an enhanced stem cell like ability for self-renewal, invasion, proliferation, tumorigenesis, drug resistance and increased expression of stem cell markers, including CD133, CD44, Oct-4 and ABCG2. Notably, although the expression levels of CD44 in sphere and parent cells were statistically different, the levels of both were increased when compared with the control group. Previous studies have reported that the significance of CD44 was also ambivalent $(27,28)$. Therefore the optimal combination of stem cells markers for specific tumors still require further examination.

CSCs may serve a role in TKI resistance. A previous study reported gefitinib resistant cells exhibited stem cell-like properties, including increase of SP and self-renewal capabilities (9). Another study by Kobayashi et al (29) reported that Oct-4, the putative stem cell marker, could induce gefitinib resistance by regulating the CSC properties in aNSCLC cell line with EGFR mutation, and the samples from patients with acquired resistance to TKIs manifested a high level of Oct- 4 expression. Similarly, cells resistant to the second generation TKI afatinib manifested CSC phenotypes, including an enhanced ability of colony formation and proliferation, and increased level of ALDH1 and CD44 (30). So it was implied that resistance to TKI could partly arise from CSCs. This was corroborated by the present study, where sphere cells were demonstrated to develop resistance to chemotherapeutic drugs and TKI. The possible mechanisms are as follows: Firstly, in EGFR mutant NSCLC, EGFR downstream signals including phosphatidylinositol 3-kinase (PI3K)/Akt are activated (31). Upon the treatment of TKIs, these signals are inhibited. Meanwhile, PI3K/Akt may serve a critical role in CSC phenotypes (32). Therefore, the abnormal activation of PI3K/Akt in CSCs may contribute to TKI resistance. Secondly, genes including Oct-4 and nanog have been demonstrated to promote EMT and therefore induce stem cell properties (33). EMT can also trigger aquired resistance of TKIs (6). CSCs are resistant to chemotherapeutic drugs, partially owing to elevated expression of drug transporters of the ATP-binding cassette (ABC) family (34). However the role of the ABC family in TKI resistance requires further study. Lastly, under the selective pressure of TKIs, parent tumor cells underwent apoptosis and multi-drug resistant CSCs were retained and enriched. In this work, after treatment of erlotinib, the elevated levels of CD133 and $\mathrm{ABCG} 2$ may reflect the elevated proportion of TKI-resistant CSCs.
MAP17 is an established oncogene working through ROS induction (12-14). The N-terminus of MAP17 is composed of 13 amino acids that encode a PDZ-binding domain (35). MAP17 can bind to a number of PDZ domain-containing proteins, including PDZK1 (NHRF3) and other NHRF proteins, and MAP17 is abnormally overexpressed in several malignancies, including laryngoesophageal, breast, lung and thyroid tumors $(12,36,37)$. Tumors overexpressing MAP17 showed increased ability for proliferation, invasion, migration and tumorigenesis, suggesting that there may be an association of MAP17 and CSC phenotypes. However, the function of MAP17 in CSCs has, to the best of our knowledge, yet to be reported. In the present study, the MAP17 level was demonstrated to be increased in sphere cells, MAP17 knockdown resulted in decreased ability of drug resistance and sphere formation, while MAP17 overexpression induced an increase in malignant phenotypes, therefore demonstrating the role of MAP17 in CSCs.

The function of MAP17 is associated with production of ROS, and dependent on the PDZ-binding domain. MAP17 protects cells from Myc-induced apoptosis through ROS-dependent activation of the PI3K/AKT pathway (38). Furthermore, MAP17 can cause the activation of AKT, independent of PI3K activity (12). Previous studies have demonstrated that MAP17 induced ROS though SGLT1 (23), and the inhibition of SGLT1 inhibits MAP17-induced ROS increase and cell proliferation (12). Furthermore, MAP17 and SGLT1 were prognostic markers for treatment with cisplatin and radiation (24). In the present study, the SGLT1 level was elevated in cells overexpressing MAP17, inhibition of SGLT1 resulted in decreased ability of sphere formation, indicating MAP17 induced CSC phenotypes, partially through ROS and dependent on SGLT1.

In conclusion, the present study suggested that CSC-like cells could be enriched under an undifferentiated suspension culture. CSC-like cells exhibit increased resistance to TKIs, and the enrichment of CSCs may be a reason for TKI resistance. MAP17 was aberrantly elevated in CSC-like cells and associated with TKI resistance, and the regulatory function of MAP17 is partially dependent on SGLT1.

\section{Acknowledgements}

Not applicable.

\section{Funding}

No funding was received.

\section{Availability of data and materials}

The datasets used and/or analyzed during the current study are available from the corresponding author on reasonable request.

\section{Authors' contributions}

YS was involved in study conception, study design, experimentation, data analysis and manuscript writing. HL conducted literature research, experiments and statistical analysis, and was involved in manuscript preparation. DZ was involved in study conception and data analysis, and reviewed the 
manuscript. QZ was involved in study conception and data analysis, and revised the manuscript.

\section{Ethical approval and consent to participate}

All procedures performed in studies involving animals were in accordance with the ethical standards of the institution or practice at which the studies were conducted.

\section{Consent for publication}

Not applicable.

\section{Competing interests}

The authors declare that they have no competing interests.

\section{References}

1. Torre LA, Bray F, Siegel RL, Ferlay J, Lortet-Tieulent J and Jemal A: Global cancer statistics, 2012. CA Cancer J Clin 65: 87-108, 2015

2. Lynch TJ, Bell DW, Sordella R, Gurubhagavatula S, Okimoto RA, Brannigan BW, Harris PL, Haserlat SM, Supko JG, Haluska FG, et al: Activating mutations in the epidermal growth factor receptor underlying responsiveness of non-small-cell lung cancer to gefitinib. N Engl J Med 350: 2129-2139, 2004.

3. Rosell R, Moran T, Queralt C, Porta R, Cardenal F, Camps C, Majem M, Lopez-Vivanco G, Isla D, Provencio M, et al Screening for epidermal growth factor receptor mutations in lung cancer. N Engl J Med 361: 958-967, 2009.

4. Mok TS, Wu YL, Thongprasert S, Yang CH, Chu DT, Saijo N, Sunpaweravong P, Han B, Margono B, Ichinose Y, et al: Gefitinib or carboplatin-paclitaxel in pulmonary adenocarcinoma. N Engl J Med 361: 947-957, 2009.

5. Jackman D, Pao W, Riely GJ, Engelman JA, Kris MG, Jänne PA, Lynch T, Johnson BE and Miller VA: Clinical definition of acquired resistance to epidermal growth factor receptor tyrosine kinase inhibitors in non-small-cell lung cancer. J Clin Oncol 28: 357-360, 2010

6. Sequist LV, Waltman BA, Dias-Santagata D, Digumarthy S, Turke AB, Fidias P, Bergethon K, Shaw AT, Gettinger S, Cosper AK, et al: Genotypic and histological evolution of lung cancers acquiring resistance to EGFR inhibitors. Sci Trans Med 3: 75ra26, 2011.

7. Yu HA, Arcila ME, Rekhtman N, Sima CS, Zakowski MF, Pao W, Kris MG, Miller VA, Ladanyi M and Riely GJ: Analysis of tumor specimens at the time of acquired resistance to EGFR-TKI therapy in 155 patients with EGFR-mutant lung cancers. Clin Cancer Res 19: 2240-2247, 2013.

8. Ghosh G, Lian X, Kron SJ and Palecek SP: Properties of resistant cells generated from lung cancer cell lines treated with EGFR inhibitors. BMC Cancer 12: 95, 2012.

9. Shien K, Toyooka S, Yamamoto H, Soh J, Jida M, Thu KL, Hashida S, Maki Y, Ichihara E, Asano H, et al: Acquired resistance to EGFR inhibitors is associated with a manifestation of stem cell-like properties in cancer cells. Cancer Res 73 3051-3061, 2013.

10. Clarke MF, Dick JE, Dirks PB, Eaves CJ, Jamieson CH, Jones DL, Visvader J, Weissman IL and Wahl GM: Cancer stem cells-perspectives on current status and future directions: AACR Workshop on cancer stem cells. Cancer Res 66 9339-9344, 2006

11. Kocher O, Cheresh P and Lee SW: Identification and partial characterization of a novel membrane-associated protein (MAP17) up-regulated in human carcinomas and modulating cell replication and tumor growth. Am J Pathol 149: 493-500, 1996.

12. Guijarro MV, Vergel M, Marin JJ, Muñoz-Galván S, Ferrer I, Ramon y Cajal S, Roncador G, Blanco-Aparicio C and Carnero A: p38 $\alpha$ limits the contribution of MAP17 to cancer progression in breast tumors. Oncogene 31: 4447-4459, 2012.

13. Di Maro G, Orlandella FM, Bencivenga TC, Salerno P, Ugolini C, Basolo F, Maestro R and Salvatore G: Identification of targets of Twist 1 transcription factor in thyroid cancer cells. J Clin Endocrinol Metab 99: E1617-1626, 2014.
14. Inoue J,OtsukiT,Hirasawa A,ImotoI,MatsuoY,Shimizu S,TaniwakiM and Inazawa J: Overexpression of PDZK1 within the 1q12-q22 amplicon is likely to be associated with drug-resistance phenotype in multiple myeloma. Am J Pathol 165: 71-81, 2004.

15. Livak KJ and Schmittgen TD: Analysis of relative gene expression data using real-time quantitative PCR and the 2(-Delta Delta $\mathrm{C}(\mathrm{T})$ ) method. Methods 25: 402-408, 2001.

16. Dontu G, Abdallah WM, Foley JM, Jackson KW, Clarke MF, Kawamura MJ and Wicha MS: In vitro propagation and transcriptional profiling of human mammary stem/progenitor cells. Genes Dev 17: 1253-1270, 2003.

17. Singh SK, Clarke ID, Terasaki M, Bonn VE, Hawkins C, Squire J and Dirks PB: Identification of a cancer stem cell in human brain tumors. Cancer Res 63: 5821-5828, 2003.

18. Al-Hajj M: Cancer stem cells and oncology therapeutics. Curr Opin Oncol 19: 61-64, 2007.

19. Liu S, Dontu G and Wicha MS: Mammary stem cells, self-renewal pathways, and carcinogenesis. Breast Cancer Res 7: 86-95, 2005

20. Boiani $M$ and Schöler HR: Regulatory networks in embryo-derived pluripotent stem cells. Nat Rev Mol Cell Biol 6: $872-884,2005$

21. Dean M, Fojo T and Bates S: Tumour stem cells and drug resistance. Nat Rev Cancer 5: 275-284, 2005.

22. Carnero A: MAP17 and the double-edged sword of ROS Biochim Biophys Acta 1826: 44-52, 2012.

23. Perez M, Praena-Fernandez JM, Felipe-Abrio B, Lopez-Garcia MA, Lucena-Cacace A, Garcia A, Lleonart M, Roncador G, Marin JJ and Carnero A: MAP17 and SGLT1 protein expression levels as prognostic markers for cervical tumor patient survival. PLoS One 8: e56169, 2013

24. Guijarro MV, Leal JF, Blanco-Aparicio C, Alonso S, Fominaya J, Lleonart M, Castellvi J, Ramon Y Cajal S and Carnero A: MAP17 enhances the malignant behavior of tumor cells through ROS increase. Carcinogenesis 28: 2096-2104, 2007.

25. Ponti D, Costa A, Zaffaroni N, Pratesi G, Petrangolini G Coradini D, Pilotti S, Pierotti MA and Daidone MG: Isolation and in vitro propagation of tumorigenic breast cancer cells with stem/progenitor cell properties. Cancer Res 65: 5506-5511, 2005.

26. Patrawala L, Calhoun T, Schneider-Broussard R, Zhou J, Claypool K and Tang DG: Side population is enriched in tumorigenic, stem-like cancer cells, whereas ABCG2+ and ABCG2- cancer cells are similarly tumorigenic. Cancer Res 65: 6207-6219, 2005

27. Leung EL, Fiscus RR, Tung JW, Tin VP, Cheng LC, Sihoe AD, Fink LM, Ma Y and Wong MP: Non-small cell lung cancer cells expressing CD44 are enriched for stem cell-like properties. PLoS One 5: e14062,2010.

28. Takanami I, Takeuchi $\mathrm{K}$ and Naruke M: Expression and prognostic value of the standard CD44 protein in pulmonary adenocarcinoma. Oncol Rep 7: 1065-1067, 2000.

29. Kobayashi I, Takahashi F, Nurwidya F, Nara T, Hashimoto M, Murakami A, Yagishita S, Tajima K, Hidayat M, Shimada N, et al: Oct4 plays a crucial role in the maintenance of gefitinib-resistant lung cancer stem cells. Biochem Biophys Res Commun 473: 125-132, 2016.

30. Hashida S, Yamamoto $H$, Shien $K$, Miyoshi $Y$, Ohtsuka T, Suzawa K, Watanabe M, Maki Y, Soh J, Asano H, et al: Acquisition of cancer stem cell-like properties in non-small cell lung cancer with acquired resistance to afatinib. Cancer Sci 106: 1377-1384, 2015

31. Ho R, Minturn JE, Hishiki T, Zhao H, Wang Q, Cnaan A, Maris J, Evans AE and Brodeur GM: Proliferation of human neuroblastomas mediated by the epidermal growth factor receptor. Cancer Res 65: 9868-9875, 2005.

32. Huang G, Yan H, Ye S, Tong C and Ying QL: STAT3 phosphorylation at tyrosine 705 and serine 727 differentially regulates mouse ESC fates. Stem Cells 32: 1149-1160, 2014

33. Wang D, Lu P, Zhang H, Luo M, Zhang X, Wei X, Gao J, Zhao Z and Liu C: Oct-4 and Nanog promote the epithelial-mesenchymal transition of breast cancer stem cells and are associated with poor prognosis in breast cancer patients. Oncotarget 5: 10803-10815, 2014.

34. Lage $\mathrm{H}$ : An overview of cancer multidrug resistance: A still unsolved problem. Cell Mol Life Sci 65: 3145-3167, 2008.

35. Lanaspa MA, Giral H, Breusegem SY, Halaihel N, Baile G, Catalán J, Carrodeguas JA, Barry NP, Levi M and Sorribas V: Interaction of MAP17 with NHERF3/4 induces translocation of the renal Na/Pi IIa transporter to the trans-Golgi. Am J Physiol Renal Physiol 292: F230-F242, 2007. 
36. de Miguel-Luken MJ, Chaves-Conde M, Quintana B, Menoyo A, Tirado I, de Miguel-Luken V, Pachón J, Chinchón D, Suarez V and Carnero A: Phosphorylation of gH2AX as a novel prognostic biomarker for laryngoesophageal dysfunction-free survival. Oncotarget 7: 31723-31737, 2016.

37. Wang N, Zhou F, Xiong H, Du S, Ma J, Okai I, Wang J, Suo J, Hao L, Song Y, et al: Screening and identification of distant metastasis-related differentially expressed genes in human squamous cell lung carcinoma. Anat Rec (Hoboken) 295: 748-757, 2012 .
38. de Miguel-Luken MJ, Chaves-Conde M, de Miguel-Luken V, Muñoz-Galván S, López-Guerra JL, Mateos JC, Pachón J, Chinchón D, Suarez V and Carnero A: MAP17 (PDZKIP1) as a novel prognostic biomarker for laryngeal cancer. Oncotarget 6: 12625-12636, 2015. 